\title{
RFID and the Innovation Cycle
}

\author{
Yossi Sheffi \\ MIT Center for Transportation and Logistics, Cambridge, MA 02139
}

April 2004

\begin{abstract}
This paper looks at several "disruptive" technologies. It traces the path they have taken from the early innovation phase to full implementation. The technologies discussed include refrigeration; the automobile and highway system; incandescent lighting; the television and the personal computer. The paper first traces each technology through several steps leading from the early innovation to wide adoption. Then the same steps are applied to RFID, placing it in this historical context and speculating on the possible future adoption and impact of this technology.
\end{abstract}

A lot has been written about the implications of RFID technology to supply chain management. In fact there was hardly a scientific or professional conference in logistics and supply chain management during 2003 and 2004 without a session on the topic. As depicted in Figure 1, ${ }^{1}$ the topic has also become prevalent in the general news and business media.[1]

Figure 1. Number of RFID Publications
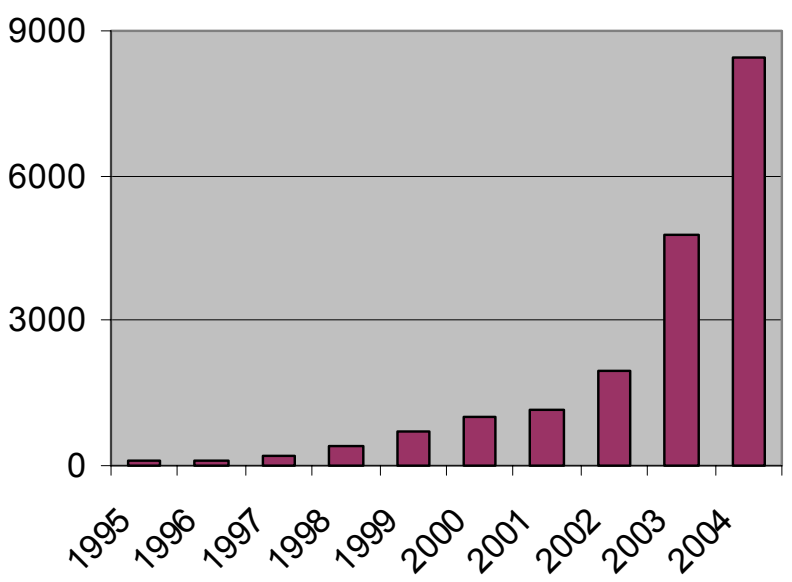

\footnotetext{
${ }^{1}$ Figure 1 is based on Factiva, a database of 8,000 news and business publications, by Dow Jones \& Reuters. The 2004 figure is annualized, based on the first two months of the year.
}

The technology aims to replace the barcode system to track items as they move through supply chains. ${ }^{2}$ Finkenzeller [2] provides a general overview of RFID technology while Sarma [3] describes the specific technology for supply chain management (see also McFarlane and Sheffi [4, 5]). An RFID-based system generally comprises the following elements:

1. A unique standard identification number assigned to a particular item.

2. Low cost identity tag which is attached to the item.

3. Networked RFID readers and data processing systems.

4. Networked data bases that store the information and enable information exchange.

\footnotetext{
${ }^{2}$ For the most part, the discussion of RFID in the context of supply chain management looks at passive RFID tags, which are excited by the reader. Unlike passive tags, much more powerful active RFID tags contain their own power source. They can be read over longer distances and can even communicate with the satellitebased global positioning system.
} 
The advantages of RFID systems over barcode systems include the following:

- Ability to have continuous information rather than at discrete points in time.

- Potentially more accurate than the bar code combination of humans and readers.

- Many tags can be read simultaneously into a computer, increasing the reading speed.

- The content of various conveyances (such as trailers, cases, pallets, shopping carts) can be read automatically without opening and sorting the content.

- More data can be stored on the tag, leading possibly to item-level information.

- RFID tags offer future possibilities for recording other data such as temperature exposure and location ${ }^{3}$

RFID hardware is now very much in active development around the world. For example, Figure 2 depicts a glovebased reader, originally developed by

Figure 2. The "iGlove"

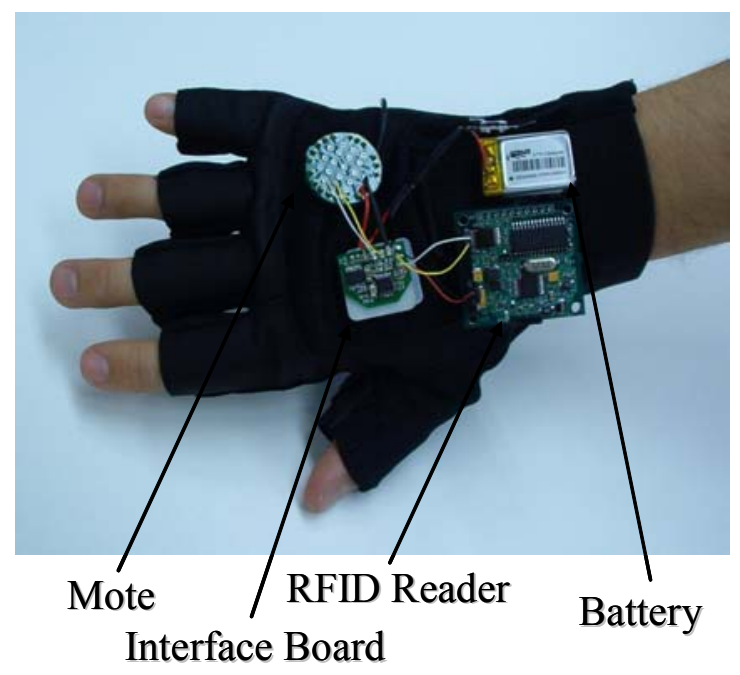

Intel Inc. and then further developed at the MIT Center for Transportation and Logistics.[6]

Despite the advantages offered by RFID-based systems, it is unclear to what extent they will replace barcodes, given the benefits offered by the existing barcode technology and its ubiquity. In addition, a number of challenges associated with the widespread adoption of RFID remain. These include the cost/benefit for some applications and interference issues for metallic products and liquids. Consequently, a number of supply chain professionals are not sure whether current RFID systems are destined to narrow "special applications" adoption or a technology that will fundamentally change supply chain management.

\section{Path of Innovation}

To take a historical perspective on the development of RFID and conjecture about the future of this technology, one can look at the path of other technological breakthroughs and try to deduce where RFID is in terms of its life cycle as an innovation. The following sections discuss five technological innovations:

- Refrigeration technology

- The automobile and highway system

- Incandescent lighting

- The television

- The personal computer

In almost all cases, one can identify six stages in the evolution of innovative disruptive technologies:

\footnotetext{
${ }^{3}$ For example, by pulsing the readers in a known sequence and measuring the time of a reading.
} 
1. The Fog of Innovation.

2. Life Support for Existing Technologies.

3. The Stamp of Approval.

4. Out with the Old.

5. It's Everywhere.

6. The Big Bang.

Not every innovation goes through all these stages. Furthermore, in most cases these stages are not followed in a clean chronological order. Instead, they are intermingled, sometimes skipped, and in many cases are difficult to identify. Yet, such somewhat anecdotal evidence may suggest where RFID is heading.

The last section places the development of RFID in the context of the six steps above, trying to assess where we are today in the innovation cycle and what can be expected in the future.

\section{The Fog of Innovation}

At this stage the innovation is young. There may be numerous companies developing many variants of the future product; the technology is adopted at this stage by small market segments where it has a clear advantage or by "early adopters." Many established players do not understand the new technology and ignore it. ${ }^{4}$ Other established players may

${ }^{4}$ The following may illustrate the point:

- A Western Union internal memo noted in 1876: "This 'telephone' has too many shortcomings to be seriously considered as a means of communication. The device is inherently of no value to us."

- A Yale University management professor remarked "The concept is interesting and well-formed, but in order to earn better than a 'C,' the idea must be feasible," in response to Fred Smith's paper proposing reliable overnight delivery service. try to discredit the technology and may attempt to erect legal and regulatory barriers to impede its progress. And indeed, the current new product or process may be too expensive and "buggy."

When ice-making machines started replacing the process of harvesting ice blocks from ponds (mainly in New England), it was difficult for ice makers to break into the market for ice. ${ }^{6}$ The reason was that the cost of harvesting ice in New England ponds in the middle of the $19^{\text {th }}$ century was quite low and the quality of the harvested ice was superior. (The harvested ice was clearer, since the mechanical process used to make ice caused air to be trapped in the ice blocks produced.) Thus, the machine-made ice took hold first in the South, where the cost of transported ice was very high, providing a natural segment for the machine-made product. Interestingly, this only seems to have expanded the market; in 1886 the ice harvest was the biggest ever [9] at 25 million tons, while the new technology continued spreading throughout the South.

Both the current system of automobile and modern roads is the result of many years of development. When the internal combustion engine was being developed in the middle of the $19^{\text {th }}$ century, horse-

\footnotetext{
${ }^{5}$ A similar description of the first stage of disruptive technology is given by Beaumont in the context of mobile phone technology in general and $3 \mathrm{G}$ in particular [7]

${ }^{6}$ The first modern ice-making machine, was patented in Britain by Perkins in 1834 (Jones [8]) The first US patent for manufacturing ice was awarded to Dr. John Gorrie of Florida in 1851, who developed the process to help cool malaria victims. The first factories were built in the South in the 1860 s.
}

Refrigeration 
drawn carriages were still the preferred mode of transportation. Driving an automobile required a high degree of technical dexterity and mechanical skill, as well as special clothing including hat, gloves, duster coat, goggles and boots. Tires were notoriously unreliable at the time, and changing one was an excruciating experience. Fuel was a problem, since gasoline was in short supply. Consequently the automobile was not seen as a general means of transportation but rather as a hobbyists' curiosity.

Early television systems were mechanical devices, generating very crude images. In 1927, Philo Farnsworth applied for patent for the first electrical television system. ${ }^{7}$ His system included both a transmitter and a receiver. David Sarnoff, chairman of the Radio Corporation of America (RCA)

\footnotetext{
${ }^{7}$ The patent was granted in 1930. Farnsworth was 24 at the time.
}

understood the potential of this invention and tried to buy him out, but Farnsworth insisted on a royalty arrangement. RCA, who was used to collecting royalties rather than paying for them [11], tried to discredit the device and the inventor, and at the same time challenged Farnsworth's patent as infringing on work carried out at RCA.

In the early days the technology was either scoffed at or ignored. Ken Olsen, founder, chairman and CEO of Digital Equipment Corporation, quipped in 1977 "there is no reason anyone would want a computer in their home..."8 IBM believed the concept to be insignificant and saw no reason to fight it. The company even decided that it could make some money manufacturing the new-fangled machines. Developing the operating system, however, was not worth its while (the system could be bought from a small company named Microsoft) and neither was developing the integrated circuit which was the electronic heart of the machine (which could be bought from Intel). ${ }^{9}$ The other major supplier of personal computers, Apple, was hardly a threat to the incumbents. At the time Apple computers could process words in capital letters only, and no secretary would swap her slick IBM Selectric typewriter for one of these troublesome machines.

\footnotetext{
${ }^{8}$ For completeness, note that Thomas Watson, chairman of IBM, remarked in 1943 "I think there is a world market for maybe five computers."

${ }^{9}$ One can only imagine the size of IBM today if it had controlled both the chip and the operating system of the PC, rather than merely produce the casings...
} 
Thus, in the early days of these innovations the fledgling technologies were generally inferior to what was already available. As a result the established leaders either did not recognize the commercial potential of these new ideas, or fought to bury them if they perceived a genuine threat.

\section{Life Support for Exiting Technologies}

At this stage two processes take place: market incumbents perceive the threat and are trying to improve the old technology in order to increase its competitiveness, while at the same time adopting some aspects of the new technology to help them sell and develop the established products (thereby prolonging their lives).

Refrigeration

As the ice making technology improved and took hold in Southern US, ice harvesters in the North found that they could harness it to make their industry more competitive. Using refrigeration technologies, they were able to move the harvested ice over long distances and increase their markets in the Far East and southern US. Thus, they were increasing their sales by using the technology that eventually replaced them.

In addition, the ice harvesters improved their processes by investing in new automation, thus cutting costs and increasing their competitive reach. These advances prolonged the existence of the ice harvesting industry by a few years.

While there do not seem to be cases in which engine technology was used to advance the cause of the horse and carriage, one of the main uses of early internal combustion engines was to help cyclists peddle their bikes. In fact, the Duryea Brothers, who were bicycle manufacturers, were the first manufacturers of gasoline powered engines ${ }^{10}$ and are generally recognized as the first American automobile manufacturers. ${ }^{11}$ Furthermore, while the automobile itself did not help the technology it replaced, many of the innovations that would make the automobile-and-highway system the dominant form of transportation were originally introduced to help its rival the horse-drawn carriage. Shock absorbers, rubber tires and roads with drainage systems, were all introduced long before the automobile, to serve the needs of the carriage business. ${ }^{12}$

In response to the invention of the incandescent lighting (which was based on a filament of carbon heated by electricity), the gas industry adopted a technology developed by Austrian inventor Carl von Welsbach that involved hitting a metal oxide filament with a gas flame. The resulting gas mantle, first introduced in 1883, increased gas lighting efficiency fivefold. Ten years later, continuous improvements reduced the costs of gas lighting by two thirds [13]. While

\footnotetext{
${ }^{10}$ The Duryea Motor Wagon Company was founded in 1896

${ }^{11}$ Even though their Duryea Motor Wagon Company made only 13 cars.

${ }^{12}$ Thomas Telford John Loudon McAdam improved the design of roads in the beginning of the $19^{\text {th }}$ century by introducing geometric design and pavement design principles. Asphalt roads were introduced in France in 1824 while the first modern asphalt road in the US was in Battery Park and on Fifth Avenue in New York City in 1872 [12].
} 
boosting sales for gas lighting at the end of the $19^{\text {th }}$ century, this invention did not prevent the ascendancy of electric lighting which finally took over at the beginning of the $20^{\text {th }}$ century. ${ }^{13}$

Interestingly, one of the first uses of electrical energy was to help the technology it eventually replaced. In 1852 the City of Boston installed electric fire alarm boxes throughout the city; they were needed to mitigate the fire hazard presented by gas and candle lighting.

In 1923, David Sarnoff predicted, in an RCA board meeting, that some day each American household would be equipped with a television that "will make it possible for those at home to see as well as hear what is going on at the broadcast station." [14]. While television did not drive radio out of existence, it certainly replaced it as the main mode mass communications and entertainment. Sarnoff's comment demonstrates the thinking at the time, that television will basically help increase the appeal of radio broadcasting by allowing the audience to watch the broadcasters as they deliver.

Early PC technology was basically used as a terminal to connect with a mainframe computer. In fact 'terminal emulation' programs are still being built into operating systems today. Furthermore, companies like Digital Equipment Corporation used the technology which eventually fueled the modern PC to develop departmental computers (such as their venerable PDP

\footnotetext{
${ }^{13}$ The gas industry did not collapse, since it found a market in space heating and a few related areas.
}

11), not realizing that they may be sowing the seeds for their own demise.

These examples demonstrate how old technology players responded initially to upstart competitors by improving their existing offerings or products. Some actually used the new technology to bolster their market positions and fend off the competitors that eventually usurped them.

\section{The Stamp of Approval}

In many cases, new technologies cannot break through until an established player decides to adopt the technology, thus giving it a "stamp of approval." This creates a marketing "buzz" and in many cases leads to the emergence of a dominant design or standard. Marketing executives refer to this as the "verification" of the new technology. In most cases it is a positive development for the new entrants even if a competitor adopts the technology since it helps convince potential customers of the need for the new product or service.

In the case of the automobile, the stamp of approval probably came from the government's push to build roads, thereby not only supporting the new automobile technology, but building an important component of the system. Well before the Interstate Highway System project, in the Model T days, the U.S. Congress and many state legislatures funded the building of roads under the slogan "get the farmers out of the mud." 14

\footnotetext{
${ }^{14}$ For example, in 1920 the Minnesota constitution was changed to enable the funding of a system of paved trunk highways, plus helping the building of county and city roads. It
} 
Light

Television

PC-S

Refrigeration
Edison's reputation as an inventor and businessman was so well-entrenched in the public mind in the late $19^{\text {th }}$ century that the mere fact that the new innovation came from him ensured that his company was successful in selling electric lighting equipment to businesses and homes.

After fighting Farnsworth for a decade, RCA acquiesced and agreed to Farnsworth's royalties arrangement for the television technology. "The RCA attorney is said to have had tears in his eyes as he signed the contract.'[14] RCA then started to push the technology, exhibiting it in the 1939 New York World's Fair. Importantly, in 1941 the US Federal Communications Commission established the standard of 525 lines per frame and 30 frames per second.

The entrance of IBM into the market for personal computers legitimized the new product for business users. The presence of Big Blue also brought competition for Apple and initially validated the new product category, helping the many PC manufacturers that sprung up in the early days of the industry to sell more products (even though many of these firms were later driven out of business).

\section{Out with the Old}

As the new technology becomes accepted, it replaces the old technology for many of the same applications.

Ice harvesting continued as a viable business until the beginning of the $20^{\text {th }}$ century, even though manufactured ice

was to be funded by a gasoline tax and a vehicle registration fee. [15] was taking over. The old industry finally died when ice boxes at homes and businesses gave way to the electric refrigerator.

The most significant impetus to the wide adoption of the automobile was probably the development of the assembly line by Ford Motor Company. This innovation was launched in 1908, and by 1927 the price of a Model T dropped from $\$ 1,000$ to $\$ 300$ per unit, even as the product improved.

In 1881 Edison demonstrated his vision by lighting large parts of lower Manhattan from a central generating station. After that, incandescent lighting took hold in homes, stores and offices all over the world.

After World War II, television broadcasts of news started replacing radio news as the main source of news for American households. The price of television sets dropped dramatically and the quality improved with the addition of color and larger sets.

The spreadsheet by VisiCalc was the first major "killer-application" that caused many accountants to buy a computer. The machines became more and more popular as they became easier to use with the addition of graphical user interface and many more applications.

\section{It's Everywhere and Beyond}

The last stage in the innovation life cycle marks the replacement of the old technology by the new one. In many cases, the new technology then inspires new applications which were impossible with the old technology.
Cars

Light

Television

PC-S 
Refrigeration

The wide adoption of refrigeration technology led to the development of the frozen food industry, by enabling a much wider variety of fresh foods to be traded and consumed out-of-season.

Cars

Light

Television

PC-s
There were 204 million cars in the US in 2001, or almost two cars per household.[16] The automobile and highway system has changed travel and vacation patterns, leading to the development of roadside motels and drive-through restaurants

Inexpensive and reliable lighting systems extended human activities into the night on a scale impossible with gas lighting. Examples include night sports, night construction activities, night driving, etc.

In 2001 there were 248 million television sets in the US, almost one per person and significantly more than one per household. It became the main source of entertainment for a growing part of the population, leading to "couch potatoes" and TV dinners.

The availability of easy-to-use applications played a key role in the widespread adoption of personal computers. These included word processing and spreadsheet programs, presentation packages and games. The expansion of the PC market also led to declining prices and accelerating market growth for these machines.

\section{Structural Changes: The Big Bang}

Many important technological innovations had their most dramatic impacts in ways that were never envisioned by the original inventors. In many cases these latent changes were orders of magnitude larger and more profound than the immediate impact.

The adoption of refrigeration meant that not only could food be stored and handled for longer periods without spoilage, but houses and workplaces could be cooled as well. The structural results of these changes were, for example (i) the industrialization of agriculture, by allowing out of season consumption and long distance shipments, making it easier to achieve economies of scale in production, and (ii) the development of the US South (as well as many other southern regions around the world), which would not have been possible without airconditioning.

The adoption of the automobile as the main mode of transportation led to the decline of urban centers as populations moved to the suburbs. In business, the flexibility and relatively low cost of truck transportation paved the way for new approaches to manufacturing, such as just-in-time. On a global level the spread of automobiles has raised air pollution levels and with it respitory diseases.

Modern lighting has encouraged the entry of other electrical appliances into the home, such as washing machines and televisions. This has promoted important social changes, since household chores have become less onerous, releasing women to pursue roles outside of domestic work. It also brought the era of the television.

Television did not only add another dimension to news reporting but
Refrigeration

\section{Cars}

Light

Television 
changed the face of news and the involvement of people in the political process. By bringing pictures of the Vietnam War, the 2001 World Trade Center attack, or the 2004 prisoners' abuse at Abu Ghuraib prison in Iraq to the world's living rooms, television images have been changing world politics. In addition, television is responsible for the rise of professional sports, the adoption of a multitude of products through advertisement, and the homogenization of the world fashion and culture.

Personal computers are responsible for the large increase in business productivity. The ease of using many PC applications (word processing, filing, presentations, etc.) meant not only an increase in productivity; office responsibilities changed, and with it the role of office workers. Performing work on a PC has led to the rise in knowledge workers and, with it, new forms of eneterprise organizations. Such organizations rely on the ability of kowledge workers to have access to information everywhere, perform the work anywhere, and communicate with their colleagues from anyplace. It also enabled the use of the World Wide Web, on line shopping, e-mail and instant messaging communications.

\section{RFID Innovation}

At this early stage of RFID innovation, it is very difficult to assess the significance of the technology. In fact, many consulting firms are advising their clients to wait rather than jump on the RFID bandwagon. This section focuses on RFID technology for supply chain management, trying to evaluate where it is in the innovation cycle in light of the examples analyzed above.

\section{The Fog of Innovation}

In the first stage of an innovation there may be several competing standards, multiple enterprises jostling for market position, and substantial doubt about the value of the new technology. Clearly, many see RFID as still in this stage. Proponents of bar codes argue that RFID does not provide significant incremental benefits, and on this basis it is difficult to justify investments in the new technology. There are still several standards competing in different regions of the world, the costs of RFID are still higher than the five cents per tag that many in the industry consider the threshold for wide-spread adoption, and there are still some technical challenges to overcome, such as interference issues when reading through metals and liquids.

In addition, the technology has raised fears of privacy intrusion, slowing down the adoption of the RFID at Benetton and others. ${ }^{15}$ Such privacy concerns are, by and large, stemming from lack of understanding of the technology, yet it caused some retail chains to investigate "kill tag" devices at their checkout counters, as well as to focus their efforts on upstream supply chain activities.

\footnotetext{
${ }^{15}$ For example, The Guardian wrote on July 13, 2003 that "One potential problem with RFID tags is that they can still work long after the product has been bought. If the tags become as ubiquitous as the manufacturers would like, people could be bristling with the chips in clothes and possessions. Anyone from police to potential thieves could work out exactly what they carry."
} 


\section{Life Support for Existing Technologies}

As the debate goes on, certain forms of automatic identification (much more powerful than RFID tags, it should be noted) are being used to enhance the value of the information collected with barcodes. For example, conveyances such as trucks are being traced using satellite-based GPS systems, while (mostly active) RFID-based readers are used to locate containers, trailers and rail cars in ports and yards. The conveyance location information is then correlated with details of the goods being carried (collected using barcodes) to complete the tracking picture.

\section{Stamp of Approval}

In June 2003 the world's largest retailer, Wal-Mart, announced that it will require its top 100 suppliers to install RFID tags in the goods sent to its distribution centers starting in January 2005. A few months later Sun Microsystems, Inc. announced that it will open an RFID test center where Wal-Mart suppliers can test their RFID solutions to guarantee compliance with the Wal-Mart standard. Another huge operator, the US Department of Defense, announced in September 2003 that it too will require its suppliers to put passive RFID tags on the lowest possible shipping element for which this makes sense (piece/ part/case/pallet/packaging) by January 2005. The statements by these enterprises - especially Wal-Mart, which is widely recognized as a technology leader - created significant momentum in the field.
At the beginning of 2003, Gillette Inc. announced the purchase of 500 million RFID tags from Alien Technology. Gillette said it was planning to use the tags with smart shelf technology to avoid pilferage, as well as for inventory management. The company has been testing the technology throughout 2003 and 2004, and this work has contributed to the buzz about the future of RFID.

However, some supporters of the technology have had to make some adjustments as their ambitious plans clashed with the reality of unstable technology and untested processes. For instance, Wal-Mart retreated from its aggressive development schedule, delaying the implementation of RFID in some pharmaceutical products which should have preceded the January 2005 implementation. The giant retailer also reduced the scope of the January 2005 top 100 suppliers' implementation, deciding instead to limit the roll-out to its Texas distribution centers.

Still, Wal-Mart's announcement has ensured that RFID technology will figure largely in the future of supply chain management, notwithstanding premature announcements on its readiness for system-wide implementation and certain technological shortcomings.

\section{Out with the Old}

As RFID gradually replaces bar codes, it will appear first in applications where the benefits justify the costs. These include the following.

- Sub-conveyance tracking: The management of these subconveyances is where the impact of 
RFID-based systems can be felt immediately. Being able to track individual pallets automatically and accurately would enable material handling companies to reduce the number of pallets in circulation, charge customers appropriately for their use on an individual pallet basis, and better maintain the pallets. Similarly, transportation and logistics companies will be able to track returnable containers and racks, thereby improving the utilization of these items. Other examples of current use of RFID in subconveyance tracking include the following [17]:

a. Scottish Courage Brewing tracks a UK inventory of 10 million beer kegs with RFID, reducing shrinkage, improving operations (shipping, receiving, payments, etc.) and providing an immediate audit trail.

b. Marks \& Spencer, the UK retailer, is using RFID to track food trays and rolling cages, cutting down the time required to read and identify these sub-conveyances by a factor of five.

c. The military has been using (active) RFID tags to track containers during the second Gulf war

- Tracking high value items: The cost of the tags is, obviously, less significant when tracking highvalue items and/or when accurate tracking is particularly important. For example, expensive items will benefit from better inventory control more than low value items. In addition, the technology has already been undergoing tests (by Gillette Inc. and Tesco Plc.) aimed at reducing theft of razor blades in retail stores. Such an application is obviously relevant to high value products at locations throughout the supply chain. Finally, RFID tags can help reduce counterfeiting of such products.

For particular industries, such as pharmaceuticals, RFID offers additional potential benefit of reducing the ability to tamper with products. In addition these products are subject to recalls which can be carried out very effectively and accurately using RFID technology. Thus, the pharmaceutical industry is likely to be one of the early adopters. ${ }^{16}$

\section{It's Everywhere}

Widespread implementation is likely to take until the end of the decade. And even at that point, it is unlikely that a complete item-level RFID code will be available on every product.

The original vision of the MIT Auto ID Center, founded in 1999 to develop an open architecture for a seamless network of physical objects, called for storing the information about all moving and stored items in a database, accessible from anywhere around the globe through the Internet. This is unlikely to take place any time soon since it is not clear that

\footnotetext{
${ }^{16}$ Accenture, one of the leading management consultants, has organized a group of pharmaceutical industry leaders, associations and government agencies as part of its "Jump Start" program to coordinate the implementation of RFID.
} 
such vast amounts of information are needed. Additionally, data ownership issues may prevent complete sharing, and there are privacy concerns that may impede the free flow of information.

But even without a complete item-level implementation it is clear that the technology can still yield major efficiency and productivity gains. RFID can lead to more accurate information gathering: what is shipped and received and what is in the warehouse and the store. It can reduce the need for manual counting at shipping/receiving docks and throughout warehouses and retail locations, as well as at checkout counters.

\section{Structural Changes}

At this point, while the technology is still nascent, it is difficult to imagine the structural changes that might unfold. By definition, these changes are not part of the current vision. Some will come into being because RFID will provide some unknown value in conjunction with others, yet-to-be invented technologies. (E-mail, for example, required both personal computers and the Internet).

On its own, one can think about RFID providing quantum leaps in the design of inventory management methods. Existing warehouses are geared for human 'put away' and pick up operations. For example, most modern warehouses use "pick to light" techniques for directing the pickers to the right bin. With RFID systems, put away locations can be determined by new, optimized trade-offs using criteria such as the efficiency of put away and picking operations, minimizing space requirements, or a combination of these criteria. Under any of these scenarios, the typical warehouse design will change drastically. No longer will items need to be stored in specific locations, so to the naked eye the warehouses will appear chaotic. However, to the electronic eye these facilities will appear wellorganized and efficiently run.

Experiments at Cambridge University show the potential of re-designing manufacturing operations [4]. In the lab, robots can read the content of partlyassembled product recipes, and change them quickly and efficiently, responding to changing requirements with little or no set-up times, thus allowing for more efficient mass customization.

Future retail operations could also change substantially. Continuous shelf inventory checking and more frequent replenishments mean that shelf space for each item can be reduced considerably, while increasing the level of service and avoiding out-of-stock situations. The result may be smaller supermarkets and other retail outlets while the number of SKUs offered remains constant. Thus, the trend towards suburban large malls may be reversed by offering all the variety of suburban supermarkets in a corner store.

Possible future interactions between personal readers (built into personal digital assistants or mobile phones) and the items in a retail location may change the way shoppers interact with retail outlets. In these futuristic stores, shoppers actually may not need to see items before purchasing them. 
As of this writing, in the middle of 2004, we are still somewhere between the first stage and the third stage of the innovation cycle of RFID. It is still not out of the Fog of innovation: the benefits of the technology are not entirely clear, especially in terms of its advantages over bar code technology. RFID does not have an assigned frequency and it interferes with some existing UHF frequencies (such as the wireless 802.11b). New communications technologies often run into standards issues and RFID is no exception, with different regions of the world using different standards. In addition, there are still questions of security, privacy and a lack of protocol for information sharing. None of these challenges seem insurmountable but they are indicative of a technology in its infancy.

Despite these hurdles Wal-Mart and most other large retailers, as well as many other organizations, including the US Department of Defense expressed their support for RFID and are going ahead with implementation plans.

\section{Beyond Supply Chains}

While it seems that RFID systems will eventually replace the barcode as the main tool for tracking products and managing inventory, the most intriguing possibilities lie in the structural changes which the technology may bring, possibly in combination with other emerging technologies. Some of the relevant related technologies include
ZigBee and WiMax [18]. ZigBee is a technology that coordinates communications among thousands of tiny sensors. These sensors can detect and transmit information about heat, moisture, particle content, forces exerted and other environmental variables from one to another and finally to a computer. WiMax is a more potent version of WiFi - it can transmit digital information at an order of magnitude faster than WiFi over distances of $25-30$ miles instead of the 100 feet or so of WiFi - thus creating "city-size" "hot spots." Like RFID these technologies work in the radio spectrum, which is free, thus promising low-cost information movement.

One of the aspects common to all the cases mentioned in this paper is that the Big Bang - the move from invention to innovation, took place when consumers adopted the technology in large numbers.

RFID, in combination with the technologies mentioned in this section, as well as and other technologies, still in the laboratory, may transform the way humans experience the world. They may lead to a sixth "digital sense" of the human environment and all the innate objects in it. Thus, one may not have to see, hear, smell, feel or taste the presence of some items, but rather sense digitally their location and condition. Such sensing may be subject to the owner's permission, creating a new social etiquette and a new way in which we all interact with each other and our environment. 


\section{References}

[1] Guitton, A., The Value of RFID in Transportation: From Greater Operational Efficiency to Collaborative Transportation Management, unpublished Master of Engineering in Logistics Thesis, MIT, Cambridge, MA, 02139.

[2] Finkenzeller, Klaus, RFID Handbook: Fundamentals and Applications in Contact-less Smart Cards and Identification, John Wiley \& Sons, 1999.

[3] Sarma, S, Towards the 5c Tag, Auto ID Center White Paper, CAM-AUTOIDWH01, www.autoidcenter.org. , 2002.

[4] McFarlane, D. and Y. Sheffi, Impact of Automatic Identification on Supply Chain Operations, International Journal of Logistics Management, Vol. 14, No.1, pp. 1-17, 2003

[5] McFarlane, D. and Y. Sheffi, Speeding the Supply Chain, Information Economic Journal, December 2003, pp $26-27$

[6] Cassett, D. and C. Hopeman, Radio Frequency Identification (RFID) in Semiconductor Manufacturing, unpublished Master of Engineering in Logistics Thesis, Massachusetts Institute of Technology, Cambridge, MA, 2004.

[7] Beaumont, M., 3G: Another Technology Cycle, Ericsson, Australia, 2002

[8] Jones, J.. America's Ice Men: An Illustrative History of the United States Natural Ice Industry, 1665 - 1925. Humble, Texas: Jobeco Books, 1984.

[9] Utterback, J., Mastering the Dynamic of Innovation, Harvard Business School Press, Boston, MA, 1994

[10] Mack, Pamela, Thomas Edison, http://people.clemson.edu/ pammack/lec122/edison.htm

[11] Barnouw, E. Tube of Plenty: The Evolution of American Television, Oxford University Press, New York, NY 1990

[12] Bellis, Mary, The History of Roads and Asphalt, http://inventors.about.com/library/inventors/blasphalt.htm

[13] Bright, Arthur, Jr., The Electric Lamp Industry: Technological Change and Economic Development from 1800 to 1947, McMillan, NY, New York, 1949

[14] Flatow, I., They All Laughed, Harper Collins, New York, NY, 1992

[15] Erik Hare: Think drivers pay the cost of roads? It's a myth, Minneapolis/St Paul StarTribune, September 7, 2003

[16] Miller, Leslie. Cars, trucks now outnumber drivers. Salon, August ${ }^{29 t h}, 2003$. 
[17] Ericson, J. (2003) RFID Rising, Line56, February $13^{\text {th }}, 2003$.

[18] Green, Heather, No Wires, No Rules, Business Week, April ${ }^{26 t h}, 2004$ 